\title{
Correction to: A biomechanical comparison of three fixation techniques in osteoporotic reverse oblique intertrochanteric femur fracture with fragmented lateral cortex
}

\author{
Gökhan Polat ${ }^{1} \cdot$ Turgut Akgül $^{1} \cdot$ Mehmet Ekinci $^{1} \cdot$ Serkan Bayram ${ }^{1}$ (I)
}

Published online: 4 March 2019

๑) Springer-Verlag GmbH Germany, part of Springer Nature 2019

\section{Correction to: \\ European Journal of Trauma and Emergency Surgery https://doi.org/10.1007/s00068-018-1061-1}

The original version of this article unfortunately contained a mistake. The acknowledgements were missing. The correct information is given below.

Acknowledgements This study was done with the financial support of the Istanbul University Scientific Research Projects (IU-BAP project number: 54732). We thank Fatih Alemdar, PhD and Yildiz Technical University Faculty of Civil Engineering for their participation in biomechanical tests and analysis.

The original article can be found online at https://doi.org/10.1007/ s00068-018-1061-1.

Serkan Bayram

dr.serkanbayram89@gmail.com

1 Department of Orthopedics and Traumatology, Istanbul

University Faculty of Medicine, Istanbul, Turkey 